\title{
The role of controllable lifestyle in the choice of specialisation among Hungarian medical doctors
}

\author{
Edmond Girasek*, Miklós Szócska, Eszter Kovács and Péter Gaál
}

\begin{abstract}
Background: Hungary has been serious facing human resources crisis in health care, as a result of a massive emigration of health workers. The resulting shortage is unevenly distributed among medical specialisations. The findings of research studies are consistent in that the most important motivating factor of the choice of the medical career and of medical specialisations is professional interest. Beyond this, it is important to examine other reasons of why students do or do not choose certain specialisations. The lifestyle determined by the chosen speciality is one such factor described in the literature.

Methods: Using convenient sampling, first year resident medical doctors from each of the four Hungarian universities with a medical faculty were asked to participate in the study in 2008. In total 391 first year resident medical doctors completed the self-administered questionnaire indicating a $57.3 \%$ response rate. On the basis of the work of Schwartz et al. (Acad Med 65(3):207-210, 1990), the specialisation fields were divided into the two main categories of noncontrollable (NCL) or controllable lifestyles (CL). We carried out a factor analysis on motivating factors and set up an explanatory model regarding the choice of $\mathrm{CL}$ and NCL specialisations.
\end{abstract}

Results: Two maximum likelihood factors were extracted from the motivational questions: "lifestyle and income" and "professional interest and consciousness". The explanatory model on specialisation choice shows that the "professional interest and consciousness" factor increases the likelihood of choosing NCL specialisations. In contrast the "lifestyle and income" factor has no significant impact on the choice of CL/NCL specialisations in the model.

Conclusions: Our results confirm the important role of professional interest in the choice of medical specializations in Hungary. On the other hand, it seems surprising that we found no significant difference in the "lifestyle and income" related motivation among those medical residents, who opted for $\mathrm{CL}$ as opposed to those, who opted for $\mathrm{NCL}$ specialisations. This does not necessarily mean that lifestyle is not an important motivating factor, but that it is equally important for both groups of medical residents.

Keywords: Medical students, Medical doctors, Specialisation, Controllable lifestyle, Career choice

\section{Background}

The availability of sufficient human resources with the appropriate skill mix is a major challenge of contemporary health systems [1]. Hungary well exemplifies this challenge, as it has been facing a serious human resources crisis, which threatens the sustainability of the health system $[2,3]$. While during the communist regime Hungary had a surplus of physicians, the number

\footnotetext{
* Correspondence: girasek@emk.sote.hu Health Services Management Training Centre, Semmelweis University, Kútvölgyi út 2, Budapest 1125, Hungary
}

of medical doctors registered to practice per 100,000 population fell below the EU-27 average by $11 \%$ in 2005 , and has remained there since then [4]. The loss of practising physicians is mainly attributable to migration. Since 2004, when Hungary joined the EU, more than 10,000 medical doctors have applied for the diploma certification needed to work abroad [5], representing one-third of the active medical workforce. Moreover, as young doctors are generally more mobile, the remaining population of physicians is aging. In 2014 55.0\% of the practising medical doctors were 50 years old or older, 
and it is projected that this number will increase to $64.4 \%$ by 2021 , if the current trend continues [6].

This is further aggravated by the inequitable distribution of the remaining doctors, both by specialisations and geographic location. According to the data of the Hungarian Central Statistical Office, the difference between the counties with the highest and lowest density of medical doctors was as high as 2.5 fold in 2014, even if we exclude Budapest, the capital of Hungary [7]. Further, the number of so-called "shortage specializations" is increasing, where it is not possible to recruit enough medical doctors to fill in the vacancies of health care providers, despite the extra compensation offered by the government. In 2016, shortage specializations included, among others, radiology, pathology, psychiatry, general and vascular surgery. From the policy perspective, therefore, it is of crucial importance for Hungary to understand the factors influencing medical career choices, including, but not limited to, the choice of specializations.

Medical career choices have been brought into the focus of research for several years, first in the USA and then in other countries. The findings are consistent that the most important motivation for the choice of the medical profession and of specialisations is professional interest, followed by the professional and scientific challenges, interpersonal, doctor-patient relations, and social aspects like income, work burden, life-style and prestige [8-11], with factors related to quality of life getting increasing attention [12].

The lifestyle determined by the chosen speciality was first mentioned in 1989 by Schwartz et al. [13], who found that an increasing number of medical doctors chose those specialisations, where the working time could be well planned. In 1990 Schwartz and his colleagues assessed 4th grade medical students by a 25 -item questionnaire focusing on their choice of specialisation [14]. In the frame of a factor analysis, they combined the response items into three motivation factors: "perceived lifestyle", "professional challenges and practice-orientation", and "altruistic values and attitudes". "Perceived lifestyle" (income, free-time and prestige) was the strongest determining factor in the choice of specialisation. They created two groups, controllable lifestyle (CL) and noncontrollable lifestyle (NCL) specialisations, on the basis of whether or not the medical doctor could control work hours, and found a significant correlation between the motivation patterns and the choice of CL or NCL specialities.

In 2003, Lind and Cendan [15] coined the term "lifestyle-friendly" specialisations and found them chosen more frequently in the USA during the period of 19822002. This increase was significantly higher among women indicating that they valued more the "lifestylefriendly" features of the job than men. Regarding trends, other researchers, such as Dorsey et al. [16] and Lambert et al. [17], arrived at the same conclusion. While Newton et al. also found lifestyle as becoming more important to medical students in their career choice, they emphasised income as another crucial factor, and the relative influence of these two factors varied considerably between specialties [18]. In the UK, Smith et al. found similar results in 2015: work-life balance became more important for junior doctors' choice of speciality [19].

Based on the previous findings, this study aims to explore the importance of lifestyle in the choice of medical specialisation in Hungary, using the CL-NCL categorisation of Schwartz et al. [14], to support policymaking in ensuring a more equitable distribution of specialists all over the country. To our knowledge, no such research has been carried out so far in Hungary.

\section{Methods \\ Participants and procedure}

Using convenient sampling, resident medical doctors from each of the four Hungarian universities with a faculty of general medicine were asked to participate in the survey.

A resident medical doctor or medical resident (in Hungarian "rezidens") is a person, who has already completed undergraduate medical education, and has been admitted to a centrally organized two-year postgraduate training program in one of the medical specialisations. At the time of our study, these positions were centrally financed, while the admission procedure, the program and the examinations were administered by one of the four Hungarian universities with a medical faculty. Residents practice medicine under the supervision of fully licensed specialists, usually in clinical departments of the university concerned or in teaching hospitals.

The self-administered questionnaire survey was carried out during the residency training. The questionnaire was distributed at the time of the final written test exams of a mandatory course for all resident doctors, as part of the exam package. One member of the research team briefly introduced the objectives of the study and explained that participation was voluntary and anonymous. In total 391 resident medical doctors in their first year of study completed the questionnaire indicating a 57.3\% response rate. In 2008 the government offered in total 682 new medical resident posts, whose $96.2 \%$ was actually filled.

We opted for convenient sampling, because there has been no list of all of the Hungarian resident doctors available, which could have been used as a sampling frame. It is important to note, that we could not achieve the total population sample, to a smaller extent because 
of refusals, but mainly because first year medical residents have been offered the choice of completing the mandatory course either in the first year or in the second year of their residency training. Due to the lack of statistical data on the study population, no comparison of our final sample was possible. Nevertheless, there has been no indication of sampling bias and the response rate suggests that this survey represents the valid motivations and opinion of first year medical residents in Hungary.

\section{Measurement instruments}

Residents completed a questionnaire containing different sections on career plans. They were asked about their motivations to become a medical doctor, the factors determining their choice of medical specialisation, and about their intention to work abroad. In this paper we focus solely on analysing the responses concerning the motivations on specialisation choice.

Although Rogers and colleagues [20] were in the process of developing a questionnaire on career choices and motivations, there was no internationally validated measurement instrument on specialisation choice at the time of our research, so we developed our own questionnaire.

We put together the set of questions and items about specialisation choices on the basis of the review of international and national literature and a qualitative study $[14,21,22]$. Twelve medical residents were interviewed to explore personal experiences for developing the questions. Based on these findings, the questionnaire was piloted with 10 medical residents, who belonged to the target group. According to their comments and the pilot-test experiences, the tool was finalised. This finetuning in most of the cases involved interpretation issues and grammatical corrections. (The questionnaire can be found in the Additional file 1.)

The motivations of specialisation choice were examined retrospectively [23], where the respondents rated 14 items (e.g. "This is my interest", "Good job opportunities", "Lifestyle") on a five-point Likert-scale. We tested the internal consistency of the specialisation choice motivation questionnaire, and found it appropriate (Cronbach-alpha $=.729)$ [24].

We identified the respondents chosen field of specialisation on the basis of the question "Which specialisation programme do you take part in order to obtain specialisation?" During the analysis the specialisation fields were grouped into two main categories: non-controllable (NCL) or controllable lifestyles (CL), based on Schwartz et al. [14]. The NCL specialities included internal medicine, family medicine, paediatrics, obstetrics-gynaecology, general surgery and surgical specialities, while CL specialities were anaesthesiology, dermatology, emergency medicine, neurology, ophthalmology, otolaryngology, pathology, psychiatry and radiology.

\section{Statistical analysis}

Non-weighted data were analysed using the SPSS 20.0 software. In the statistical analysis descriptive statistics, frequencies, crosstabs and means, were calculated. In line with Allen and Seaman [25], who argue that a Likert-scale can be considered an interval variable, if the interval is the attribute of the data (there are numerical values) and has at least 5 categories, and similarly to other papers of the study $[11,26]$, we analysed the five scale Likert-scale questions as interval variables, calculating their means and standard deviations. The next step was confirmatory factor analysis, Maximum likelihood with Varimax rotation. Finally, binary logistic regression tests were carried out to build an explanatory model for the lifestyle of the given speciality (NCL or $\mathrm{CL}$ ), where the independent variables were the extracted specialisation choice factors.

We assumed that those respondents, who opted for CL specialties would rate lifestyle-related specialization choice factors higher, and there would be a statistically significant difference between the two groups of medical residents in this respect.

\section{Results}

Table 1 shows the basic socio-demographic features, namely, the gender and age distribution of respondents. Over two-thirds $(68.3 \%)$ of the respondent first year resident doctors were female and $31.7 \%$ male. Regarding the age distribution, only $13.8 \%$ of the respondents were 30 years old or over, while the $86.2 \%$ majority was divided roughly equally among the $24-26$ and $27-29$ age groups. The geographical distribution shows that $51.2 \%$ of first year students were from Semmelweis University, Budapest, 22.5\% from the University of Debrecen, 16.5\% from the University of Pécs and 9\% from the University of Szeged.

\section{Descriptive statistics of specialisation choice}

Table 2 provides a simple descriptive statistics of the answers for question D3 of the questionnaire, including the mean, standard deviation and standard error for each response items. The question and the predefined motivational items, which were to be rated on a fivelevel rating scale, are presented in accordance with the

Table 1 Gender and age distribution of respondents

\begin{tabular}{lllll}
\hline & $24-26$ years & $27-29$ years & 30 years or more & Total \\
\hline Male & 46 & 54 & 17 & 117 \\
& $39.3 \%$ & $46.2 \%$ & $14.5 \%$ & $100.0 \%$ \\
Female & 119 & 99 & 34 & 252 \\
& $47.2 \%$ & $39.3 \%$ & $13.5 \%$ & $100.0 \%$ \\
Total & 165 & 153 & 51 & 369 \\
& $44.7 \%$ & $41.5 \%$ & $13.8 \%$ & $100.0 \%$ \\
\hline
\end{tabular}


Table 2 Mean, standard deviation and standard error of specialisation choice motivation items, derived from question D3 of the questionnaire (decreasing order of importance, the numbering of the items indicates the order of items in the questionnaire)

\begin{tabular}{lllll}
\hline D3 & $\begin{array}{l}\text { Please evaluate the following } \\
\text { items according to the extent } \\
\text { they influenced your choice of } \\
\text { specialization (1 = not at all, } \\
5 \text { = definitive influence)! }\end{array}$ & Mean & $\begin{array}{l}\text { Standard } \\
\text { deviation }\end{array}$ & $\begin{array}{l}\text { Standard } \\
\text { error }\end{array}$ \\
\hline 1 & Focus of my interest & 4.26 & 1.02 & 0.05 \\
2 & Professional challenges & 3.82 & 1.16 & 0.06 \\
13 & Relation with patients & 3.55 & 1.37 & 0.06 \\
9 & Lifestyle & 2.83 & 1.42 & 0.06 \\
11 & Innovation opportunities & 2.68 & 1.39 & 0.06 \\
14 & Good job opportunities & 2.65 & 1.22 & 0.04 \\
12 & Social prestige & 2.51 & 1.26 & 0.06 \\
7 & Opportunities to work abroad & 2.41 & 1.34 & 0.07 \\
5 & Prestige among medical doctors & 2.35 & 1.20 & 0.07 \\
3 & Scientific career & 2.10 & 1.17 & 0.07 \\
4 & It just happened this way & 2.10 & 1.47 & 0.07 \\
10 & Salary & 1.96 & 1.11 & 0.08 \\
8 & Family influence & 1.84 & 1.16 & 0.07 \\
6 & Informal payment & 1.44 & 0.85 & 0.06 \\
\hline
\end{tabular}

original questionnaire. The only difference is that order of the response items has been changed, the results are shown in a decreasing order of importance, while the numbering of the items indicates the order of items in the original questionnaire. This numbering is used consistently throughout the presentation of other findings.

Table 3 shows the mean values for each item separately for male and female respondents. Items, where statistically significant differences can be observed (at $p<0.05$ ), are marked with an asterisk. Three items were rated significantly higher by men ("prestige among medical doctors", "informal payment", "salary"), while two items by women ("lifestyle", "relation with patients"). These differences changed the rank order only in the case of two of these five items: "lifestyle" occupies the 4th place among women as opposed to the 7th place among men, while "prestige among medical doctors" is the 9th among women, while the 8th among men.

\section{Specialisations choice - factor analysis}

The Maximum likelihood factors were extracted from the motivational questions on specialisation choice. Table 4 shows the extracted factor structure. The first factor, which we named "lifestyle and income", consists of the following variables: "salary" (0.769), "social prestige" (0.647), "good job opportunities" (0.634), "prestige among medical doctors" (0.528), "lifestyle" (0.548), "informal payment" (0.484), "opportunities to work abroad" (0.465).
Table 3 Comparison of the means of specialisation choice motivation items by gender (the significant differences, at $p<0.05$, marked with asterisk, the numbering of items indicates the order of items in the questionnaire)

\begin{tabular}{llll}
\hline & & Male & Female \\
\hline 1 & Focus of my interest & 4.26 & 4.26 \\
2 & Professional challenges & 3.86 & 3.81 \\
13 & Relation with patients* & $\mathbf{3 . 2 3}$ & $\mathbf{3 . 7 3}$ \\
11 & Innovation opportunities & 2.84 & 2.61 \\
14 & Good job opportunities & 2.78 & 2.58 \\
12 & Social prestige & 2.68 & 2.45 \\
$\mathbf{9}$ & Lifestyle* & $\mathbf{2 . 6 1}$ & $\mathbf{2 . 9 3}$ \\
$\mathbf{5}$ & Prestige among medical doctors* & $\mathbf{2 . 5 7}$ & $\mathbf{2 . 2 5}$ \\
7 & Opportunities to work abroad & 2.52 & 2.34 \\
4 & It just happened this way & 2.16 & 2.07 \\
3 & Scientific career & 2.14 & 2.08 \\
10 & Salary* & $\mathbf{2 . 1 2}$ & $\mathbf{1 . 8 7}$ \\
8 & Family influence & 1.95 & 1.79 \\
6 & Informal payment* & $\mathbf{1 . 6 5}$ & $\mathbf{1 . 3 4}$ \\
\hline
\end{tabular}

The second factor, which we named "professional interest and consciousness" consists of the variables of "focus of interest" (0.999), "professional challenges" (0.662) and "it just happened this way" $(-0.715)$.

\section{Motivation factors and gender differences}

We compared the mean of the maximum likelihood factors in terms of gender differences, and found that men had a significantly higher value on the "lifestyle and income" factor (Table 5), i.e. their choice of specialization are influenced more by the motivational factors aggregated in this category. This finding is in line with the gender differences observed before insofar as 4 out of the 5 statistically significant differences were

Table 4 Maximum likelihood factors on specialisation choice

\begin{tabular}{llll}
\hline & Variables & $\begin{array}{l}\text { ML factor 1 } \\
\text { Lifestyle } \\
\text { and income }\end{array}$ & $\begin{array}{l}\text { ML factor 2 } \\
\text { Professional interest } \\
\text { and consciousness }\end{array}$ \\
\hline 1 & Focus of my interest & -0.030 & $\mathbf{0 . 9 9 9}$ \\
2 & Professional challenges & 0.129 & $\mathbf{0 . 6 6 2}$ \\
4 & It just happened this way & 0.086 & $-\mathbf{0 . 7 1 5}$ \\
5 & Prestige among medical doctors & $\mathbf{0 . 5 2 8}$ & 0.098 \\
6 & Informal payment & $\mathbf{0 . 4 8 4}$ & -0.129 \\
7 & Opportunities to work abroad & $\mathbf{0 . 4 6 5}$ & -0.049 \\
9 & Lifestyle & $\mathbf{0 . 5 4 8}$ & 0.045 \\
10 & Salary & $\mathbf{0 . 7 6 9}$ & -0.002 \\
12 & Social prestige & $\mathbf{0 . 6 4 7}$ & 0.132 \\
14 & Good job opportunities & $\mathbf{0 . 6 3 4}$ & -0.027 \\
\hline
\end{tabular}


Table 5 Mean value of Maximum likelihood factors on specialisation choice motivation - breakdown by gender (significant difference is marked with asterisk)

\begin{tabular}{lll}
\hline & Lifestyle and income* & $\begin{array}{l}\text { Professional interest and } \\
\text { consciousness }\end{array}$ \\
\hline Male & 0.1552533 & 0.0065065 \\
Female & -0.0739347 & 0.0087769 \\
\hline
\end{tabular}

experienced in the case of those variables, which came under the "lifestyle and income" factor.

\section{The association of motivation factors with the} controllability of the lifestyle of the chosen speciality

We set up the explanatory model in three steps (see Table 6). The first model examined the relationship between the two factors and the choice of CL versus NCL specialisations. This explanatory model on specialisation choice shows that the "professional interest and consciousness" factor has significant impact on the CL/ $\mathrm{NCL}$ specialisation choice $(\mathrm{OR}=1.534, p<0.000)$, so higher scores on motivations belonging to the "professional interest and consciousness" factor increase the likelihood of choosing non-controllable-lifestyle specialisations. The Nagelkerke R-square, which represented the goodness-of-fit of the model, was 0.035 . On the other hand the "lifestyle and income" factor had no significant impact on CL/NCL specialisation choice in the model $(\mathrm{OR}=1.150 ; p>0.05)$.

In the second model, we included gender, and in the third model age, as well, as relevant background factors (given that we had a population, which were homogenous in terms of education and occupation, and we had no data on income) and looked at how it altered the results of the first model. As it can be seen in Table 6 the odds ratios were changed only slightly, and the conclusion remained the same. Nevertheless, the Nagelkerke R-square increased to 0.064 with gender included and further to 0.073, with gender and age included, which implies the predictive power of the second model is higher and the third model is the highest.

\section{Discussion}

In the era of technological revolution in medicine accompanied by the increasing need of more and more specialized workforce, investigating the motivations of specialisation choice can be considered an even more important research topic, than the choice of the medical profession itself. Knowing why medical graduates do or do not choose specific specialisations could inform policy making aimed at a more equitable distribution of the medical workforce in a country. Hungary and other countries with a health workforce crisis are especially in need for such research to understand, where should be intervened in the health system and how.

The relationship between lifestyle and medical specialisation choice was first raised by Schwartz et al. in 1989 [13]. They provided an interesting theoretical framework of mapping medical specialisation choice [14], which was used as the basis of our study. According to the findings of Schwartz et al., we also categorized the specialities into two groups, first, where the lifestyle was under the control of the specialist (CL specialities) and second, where it was not (NCL specialities). Our study found two complex motivational factors, confirming a similar factor structure to that of Schwartz et al. The first factor of Schwartz et al., "perceived lifestyle", by and

Table 6 Binary logistic regression - explanatory models for CL/NCL specialisation choice

\begin{tabular}{|c|c|c|c|c|c|c|}
\hline & $\mathrm{B}$ & S.E. & Wald & df & Sig. & Odds ratio $(\mathrm{OR})$ \\
\hline \multicolumn{7}{|l|}{ Model 1} \\
\hline Lifestyle and income & 0.140 & 0.122 & 1.315 & 1 & 0.251 & 1.150 \\
\hline Professional interest and consciousness & 0.428 & 0.120 & 12.671 & 1 & 0.000 & 1.534 \\
\hline Constant & -0.216 & 0.110 & 3.863 & 1 & 0.049 & 0.806 \\
\hline \multicolumn{7}{|l|}{ Model 2 (with gender included) } \\
\hline Lifestyle and income & 0.110 & 0.124 & 0.786 & 1 & 0.375 & 1.116 \\
\hline Professional interest and consciousness & 0.426 & 0.121 & 12.425 & 1 & 0.000 & 1.531 \\
\hline Gender & -0.362 & 0.236 & 2.349 & 1 & 0.125 & 0.697 \\
\hline Constant & 0.403 & 0.409 & 0.972 & 1 & 0.324 & 1.497 \\
\hline \multicolumn{7}{|l|}{ Model 3 (with gender and age included) } \\
\hline Lifestyle and income & 0.148 & 0.126 & 1.394 & 1 & 0.238 & 1.160 \\
\hline Professional interest and consciousness & 0.434 & 0.123 & 12.421 & 1 & 0.000 & 1.544 \\
\hline Gender & -0.412 & 0.242 & 2.892 & 1 & 0.089 & 0.663 \\
\hline Age & 0.045 & 0.053 & 0.721 & 1 & 0.396 & 1.046 \\
\hline Constant & -0.752 & 1.535 & 0.240 & 1 & 0.624 & 0.471 \\
\hline
\end{tabular}


large covers the same motivational variables (income, free-time and prestige) as our first factor "lifestyle and income" (salary, informal payment; lifestyle; social prestige, prestige among medical doctors). The exception is job opportunities, including opportunities to work abroad, which is partly a Hungarian special related to the recent trend of the emigration of medical doctors mainly to more affluent member states of the EU. The second factor in the model of Schwartz et al, "professional challenges and practice-orientation" overlaps with our "professional interest and consciousness" factor. The other difference between our model and the model of Schwartz et al., is a third factor, "altruistic values and attitudes", which was not confirmed by the Hungarian data.

Previous studies [14-18] that found an increase in choosing "lifestyle-friendly" specialisations, underlined the importance of lifestyle-related factors in specialisation choice. Given that our study did not look at the trends, we could detect the increased significance of "lifestyle and income" only indirectly, in that the factor analysis produced a separate motivational factor for related motivational items (i.e. salary, social prestige, good job opportunities, prestige among medical doctors, lifestyle, informal payment, opportunities to work abroad).

Our binary logistic regression explanatory model on specialisation choice showed that only the "professional interest and consciousness" factor had significant impact on the choice of CL/NCL specialisations and not the "lifestyle and income" factor. Although unexpected, this does not necessarily mean that lifestyle is not an important motivating factor, but that it is equally important for medical residents choosing the $\mathrm{CL}$ as well as for those choosing NCL specialisations. This would suggest that policy makers should focus more on those life-style related factors, which are amenable to policy making. It is also possible that the original USA categorisation of specialisations does not fully fit the Hungarian health system and needs to be refined.

In summary, we managed to confirm the existence of two complex motivation factors in Hungary, similar to the model of Schwartz et al., and found the same significant association between the "professional interest and consciousness" factor and the choice of NCL specialisations as Schwartz et al. did. The apparent lack of significant association between the "lifestyle and income" factor and the choice of CL specialisations needs to be studied further, though, before any strong conclusions can be drawn regarding its real influence on medical specialisation choice.

\section{Conclusions}

The phenomenon of specialisation choice is a topic with high importance in health policy and health education. In our research we studied the topic in the framework published by Schwartz et al. [14], and found many similarities regarding the motivations of specialisation choice of Hungarian and USA medical residents, but also a few notable differences. While our study confirmed the importance of two complex motivation factors, the "professional interest and consciousness" and the "lifestyle and income" factors, it did not do in the case of the third factor of Schwartz et al. [14]. Further, while the "professional interest and consciousness" factor and the choice of NCL specialisations showed a significant association, the same was not true for the "lifestyle and income" factor and the choice of CL specialisations. This could be explained by not just its low importance, but also by an equally high importance in both groups of medical residents, which underlies the need for further research and clarification.

In order to decrease the inequalities across specialisations by addressing the shortages of professionals in certain specialties, health policy decision-makers should monitor the main motivations of medical doctors and the changes over time. Interventions regarding income and working conditions might make certain specialties more attractive, and could ultimately contribute to a better performing health care system.

\section{Additional file}

Additional file 1: Human Resource Research in Healthcare -

Questionnaire. (PDF 224 kb)

\section{Abbreviations}

CL: Controllable lifestyle; EU: European Union; NCL: Non-controllable lifestyle; USA: United States of America

\section{Acknowledgements}

Not applicable.

Funding

The research project was made possible by a grant (OFA/7341/0032) from the Hungarian National Employment Foundation (Országos Foglalkoztatási Közalapítvány). The funding body did not have any role in the design of the study and collection, analysis, and interpretation of data and in writing the manuscript.

\section{Availability of data and materials}

The data is not available, because the respondent of the survey did not consent for the publication of personal-level data file. The respondent consent for publication of the aggregated result of the study.

\section{Authors' contributions}

EG reviewed the literature, participated in the design of the study and in the data collection, performed the data analysis and put together the first draft of the manuscript. MSZ put together the conceptual framework of the study and its policy relevance. EK helped drafting and editing the manuscript. PG supervised the study, reviewed and edited the first draft and put together the final version of the manuscript. All authors have read and approved the final version of this manuscript.

Ethics approval and consent to participate

Not applicable. According to Hungarian Law there is no need to request ethical approval for this type of survey study. 


\section{Consent for publication}

Not applicable.

\section{Competing interests}

The authors declare that they have no competing interests.

\section{Publisher's Note}

Springer Nature remains neutral with regard to jurisdictional claims in published maps and institutional affiliations.

Received: 5 April 2017 Accepted: 31 October 2017

Published online: 13 November 2017

\section{References}

1. World Health Organization. Working together for health: the world health report 2006. In: The world health report. Geneva: WHO; 2006.

2. Gaál P, Szigeti S, Csere M, Gaskins M, Panteli D. Hungary: health system review. Health Syst Transit. 2011;13(5):266.

3. Gaál P, Szigeti S, Panteli D, Gaskins M, Ginneken E. Major challenges ahead for Hungarian healthcare. Br Med J. 2011;343

4. Hungarian Central Statistical Office: Number of medical doctors (2000- ). In Edited by STADAT Statistical Database, 2016 . Budapest: Hungarian Central Statistical Office; 2016.

5. Health Registation and Training Centre: Statistics about internationa mobility of health professionals. In: Migration statistics,. Budapest: Health Registation and Training Centre; 2016: 2017.

6. Ragány K, Girasek E. Simulation model of Hungarian health workforce. In: Hungarian National Health Workforce Clearing House workshop: 2012. Budapest: Semmelweis University; 2012.

7. Hungarian Central Statistical Office. Yearbook of health statistics 2014 Budapest: Hungarian Central Statistical Office; 2016.

8. Khater-Menassa B, Major S. Factors influencing the choice of specialty among medical students in Lebanon. J Med Liban. 2005:53(1):16-20.

9. Avgerinos ED, Msaouel P, Koussidis GA, Keramaris NC, Bessas Z, Gourgoulianis K. Greek medical students' career choices indicate strong tendency towards specialization and training abroad. Health Policy. 2006; 79(1):101-6.

10. Szényei G, Adám S, Gyorffy Z, Harmatta J, Túry F. A hazai pszichiáterek pálya- és jövőképe. Psychiatr Hun. 2010;25(1):31-54.

11. Girasek E, Molnár R, Eke E, Szócska M. The medical career choice motivations - results from a Hungarian study. Cent Eur J Med. 2011;6(4):502-9.

12. Lefevre JH, Roupret M, Kerneis S, Karila L. Career choices of medical students: a national survey of 1780 students. Med Educ. 2010;44(6):603-12.

13. Schwartz RW, Jarecky RK, Strodel WE, Haley JV, Young B, Griffen WOJ. Controllable lifestyle: a new factor in career choice by medical students. Acad Med. 1989;64(10):606-9.

14. Schwartz RW, Haley JV, Williams C, Jarecky RK, Strodel WE, Young B, Griffen WOJ. The controllable lifestyle factor and students' attitudes about specialty selection. Acad Med. 1990;65(3):207-10.

15. Lind DS, Cendan JC. Two decades of student career choice at the University of Florida: increasingly a lifestyle decision. Am Surg. 2003;69(1):53-5.

16. Dorsey $E$, Jarjoura D, Rutecki $G$. Influence of controllable lifestyle on recent trends in specialty choice by US medical students. J Am Med Assoc. 2003:290:1173-8.

17. Lambert $\mathrm{E}, \mathrm{Holmboe} \mathrm{E}$. The relationship between specialty choice and gender of U.S. medical students, 1990-2003. Acad Med. 2005;80:797-802

18. Newton D, Grayson M, Foster Thompson L. The variable influence of lifestyle and income on medical students' career choices: data from two U.S medical schools, 1998-2004. Acad Med. 2005;80:809-796.

19. Smith F, Lambert TW, Goldacre MJ. Factors influencing junior doctors' choices of future specialty: trends over time and demographics based on results from UK national surveys. J R Soc Med. 2015;108(10):396-405.

20. Rogers ME, Creed PA, Searle J. The development and initial validation of social cognitive career theory instruments to measure choice of medical specialty and practice location. J Carr Asses. 2009;17(3):324-37.

21. Csákó M. Zárójelentés - Felsőfokú továbbtanulás meghatározóinak kutatásról (kézirat). Budapest: ELTE Szociológia Intézet; 1998.

22. Center for Health Workforce Studies. Residency training outcomes by Speciality in 2008 for New York: a summary of responses to the 2008 New York resident exit survey. New York: Center for Health Workforce
Studies, School of Public Health, University of Albany, State University of New York; 2009.

23. Dex S. Life and work history analyses: qualitative and quantitative developments. London: Routledge; 1991.

24. Field A. Discovering statistics using SPSS. London: SAGE Publications; 2005.

25. Allen IE, Seaman CA. Likert scales and data analyses. Qual Prog. 2007; 40(7):64-5.

26. Girasek E, Eke E, Szócska M. Analysis of a survey on young doctors' willingness to work in rural Hungary. Hum Resour Health. 2010;8(1):13.

\section{Submit your next manuscript to BioMed Central and we will help you at every step:}

- We accept pre-submission inquiries

- Our selector tool helps you to find the most relevant journal

- We provide round the clock customer support

- Convenient online submission

- Thorough peer review

- Inclusion in PubMed and all major indexing services

- Maximum visibility for your research

Submit your manuscript at www.biomedcentral.com/submit
Biomed Central 